Marvin $^{3}$ in 1926 found it almost equally effective in sinus rhythm as in atrial fibrillation. Indeed Sir Thomas Lewis ${ }^{4}$ stated in 1946 that digitalis was generally recognised to be of value in failure with sinus rhythm.

In our study 16 of the 46 patients deteriorated clinically on placebo. In the remainder an increase in airways resistance, reversed by reintroduction of digoxin, was demonstrated. This reversible airways obstruction (asthma) may have progressed to overt pulmonary oedema had the placebo phase been extended. Digoxin also improved left ventricular function in a random sample from those in sinu rhythm who did not deteriorate clinically on placebo, as evidenced by shortening of left ventricular ejection time.

Thirteen of the patients studied were in atrial fibrillation, there being similar proportions among those who deteriorated clinically on placebo $(4 / 16)$ and those who did no (9/30). All the patients in fibrillation had impaired atrioventricular conduction. Far from requiring digoxin to control their ventricular rate, six of these developed bradycardia at serum digoxin concentrations recommended for control of fibrillation. The study shows the value of maintenance digoxin after an episode of failure not only in patients in sinus rhythm but also in "slow fibrillators," in whom a lower serum digoxin concentration is recommended.

R JOHN DOBBs

University College Hospital

Medical School

W I KENYON

Tameside General Hospital Ashon-under-L,yne, Lanes

Sylvia M DOBBS

Middlesex Hospital Medical School

Iondon $W_{1}$

Mackenzie, J, Diseases of the Heart, p 282. Oxford, Oxford Lniversity Press, 1910

W'indle, D, Quarterly fournal of Medicine, 1917, 10

274.
Marvin, H .M, Fournal of Clinical Investigation, 1926 3,521

Diseases of the Heart, p 39. London, Macmillan, 1946.

\section{Anonymous barbs}

SIR,-I must deplore the editorial policy of allowing the author of Personal View (16 April, p 1026) to hide behind anonymity while firing his barbs into anaesthetists and nursing personnel. With respect to the former it is, of course, poor medical practice to omit a preoperative visit, but such an omission is a littl less than credible in this age of increased patient enlightenment. Nevertheless, I think that Personal View is an inappropriate forum for such remarks presented in this fashion. I hope that the author's practice of surgery would bear similar critical review by his colleagues, anonymously, of course.

ROger J BAgShaW

\section{Department of Anaesthesia,}

University of Pennsylvania.

\section{Adjunctive chemotherapy and breast carcinoma}

SIR,-Premature reporting of the results of adjunctive chemotherapy in carcinoma of the breast has done untold damage to clinical trials in general and the management of carcinoma of the breast in particular.
When survival is the end point of a trial results should not be published for at least five years. With regard to adjunctive chemotherapy in carcinoma of the breast the idea is to prevent the colonisation of micrometastases. In view of the so-called doubling time of the malignant cell, then should patients die within the first three years it is obvious that bulk metastases were already present at the time of treatment. Our present methods of treatment are not sufficiently adequate to cure bulk metastases and therefore three-year survival rates are meaningless. It is probably unlikely that drugs can have much effect on malignant cells which may be in a resting phase, but as long as there is a slight possibility that results may be improved then the present trials must be allowed to continue.

\section{J GARRET}

Mersey Regional Centre for

Radiotherapy and Oncology,

Clatterbridge Hospital,

Bebington, Wirral,

Merseyside

\section{The thyroid and the psychiatrist}

SIR,-You state in your leading article on this subject (9 April, p 931) that few psychiatrists would agree with Asher that psychotic states secondary to myxoedema are common and often missed. Asher's view may be correct, but only a few surveys of thyroid function in psychiatric patients have been reported.

We assessed thyroid function in 98 unselected female psychiatric admissions and found four cases of hypothyroidism, of which only one had been recognised clinically. ${ }^{1}$ Routine screening for thyroid disease in women over the age of 40 presenting for the first time with a psychotic disorder might be well worth while.

G NicholsoN

University Department of

$$
\begin{aligned}
& \text { Medicine, } \\
& \text { Ninewells Hospital, }
\end{aligned}
$$

Dunde

1 Nicholson, G, Liebling, L I, and Hall, R A, British fournal of Psychiatry, 1976, 129, 236.

\section{Cost of ECG electrodes}

SIR,-Disposable pre-gelled electrodes with a large adhesive surface are now commonly used in electrocardiographic monitoring. NHS expenditure on these electrodes cannot be insignificant and we consider that their cost and performance merit careful scrutiny.

We know of 12 brands of pre-gelled disposable electrode on the UK market. Two of these are British products and all but one of the remainder are manufactured in the USA. Although we estimate that the cost of raw materials is unlikely to exceed $10 \mathrm{p}$, current prices range from 25 to $38 \mathrm{p}$, with an average of $32 \mathrm{p}$ per electrode. On the important, but not necessarily valid, assumption that the electrodes remain in place the average cost of monitoring a patient with a three-lead system is thus $96 \mathrm{p}$.

Comparisons on which those responsible for purchasing disposable electrodes could base a decision are needed but are not at present available. In a preliminary study of 12 pre-gelled electrodes we have found the performance of the majority to be broadly similar but have identified two electrodes which are inferior because of poor adhesion or a tendency to produce frequent skin reactions.

At a time when the number of patients monitored is increasing methods of limiting NHS expenditure on ECG electrodes should be explored. We suggest that it should not be impossible to develop a reliable, highperformance, reusable or partially reusable monitoring electrode. In the short term the cost of disposable pre-gelled electrodes might be reduced if these were manufactured under contract to the NHS.

Christine RoDger ROBERT RAILTON ANGELA WALSH H DONALD

Monklands District Genera Hospital,

\section{Double-blind trials and the patient}

SIR,-The double-blind trial of drugs is an established and widely used procedure. Difficulty may arise when an intelligent patient inquires what therapy is being used, and the experimenter must make his own ethical decision about the answer to be given. Sometimes, however, the new drugs may interact with other therapy to which the patient may be exposed elsewhere. It would seem, therefore, that whenever any patient is entered into any programme where this method is being used, provision should be made for full information to be available at any time from the trial centre on the drugs or placebo given to any individual involved or even for patients to be informed that they are part of such a trial. Although this may be inconvenient to researchers, the provision of a suitable card giving details of the centre and information source would seem a small price to pay for the safety it would help provide.

George T Watts

General Hospital

Birmingham

\section{Oestrogen-like effect of tamoxifen on} vaginal epithelium

SIR,-Tamoxifen is an antioestrogenic compound used in breast malignancy. It is known for its binding to oestrogen receptors, ${ }^{2}$ : is capable of some oestrogen-like or antioestrogen effects in experimental models, and is probably effective also in antagonising prolactin secretion. ${ }^{4}$ The difference between oestrogen and tamoxifen stimulation of certain target cells seems to be the lack of replenishment of oestrogen receptors in tamoxifenstimulated target cells.

In our unit 86 postmenopausal women with late breast malignancy have been treated with $30-40 \mathrm{mg}$ of tamoxifen orally per day. All the patients had proved resistant to previous standard endocrine treatment and to multiple chemotherapy. All previous hormone treatment had been stopped at least two months before tamoxifen administration was started.

In 35 cases vaginal smears were taken just before and again after 30-45 days of tamoxifen treatment. From the smears the percentage of pyknotic cells (KPI), a good index of oestrogen activity, was calculated. ${ }^{5}$ In fertile normal women the index ranges in our experience from $40 \%$ to $80 \%$ during the proliferative phase of the menstrual cycle 